\title{
Strange-but-True: a (Quick) New Argument for Contextualism about 'Know'
}

\section{Paul Dimmock}

\begin{abstract}
A powerful objection to subject-sensitive invariantism (SSI) concerns various 'strangebut-true' (or "embarrassing") conditionals. One popular response to this objection is to argue that strange-but-true conditionals pose a problem for non-sceptical epistemological theories in general. In the present paper, it is argued that strange-but-true conditionals are not a problem for contextualism about 'know'. This observation undercuts the proposed defence of SSI, and supplies a surprising new argument for contextualism.
\end{abstract}

\section{Keywords}

Epistemic Contextualism; Subject-Sensitive Invariantism; Embarrassing Counterfactuals; Fake Barn Cases

\section{Introduction}

A powerful objection to subject-sensitive invariantism (SSI) concerns various 'strangebut-true' (or "embarrassing") conditionals. Subject-sensitive invariantists propose that knowledge is constitutively tied to traditionally 'non-epistemic' factors, such as the subject's stakes or the error possibilities salient to the subject. ${ }^{1}$ An immediate consequence of such proposals is that knowledge can come and go merely with changes in

\footnotetext{
${ }^{1}$ For exposition and defence of SSI, see e.g. Hawthorne 2004: ch. 4, Stanley 2005, Fantl \& McGrath 2007, Weatherson 2012, 2017. Note that forms of SSI that tie knowledge to practical factors, such as stakes, are often called 'Interest Relative Invariantism' (IRI).
} 
those 'non-epistemic' factors. This suggests that utterances of (1) and (2), for example, could easily be true:

(1) He knows that the final score was 2-0. But if he had more at stake, he wouldn't know that the final score was $2-0$.

(2) She knows that the table is red. But if she was considering the possibility that the table is white but illuminated by red lights, she wouldn't know that the table is red. ${ }^{2}$

However, such utterances seem strange. Our judgment that such utterances seem strange would appear to indicate that knowledge does not come and go merely with changes in 'non-epistemic' factors, such as stakes and salient error possibilities, and that SSI is therefore false. ${ }^{3}$

(1) and (2) feature subjunctive (counterfactual) conditionals. The problem extends to examples involving indicative conditionals as well. For example, suppose Tom believes that the final score was 2-0 on the basis of listening to a radio announcement. Given SSI, it seems that a speaker could truly utter (3).

(3) If Tom doesn't have much at stake, he knows the final score was 2-0. But if he has a lot at stake, he doesn't know the final score was 2-0.

\footnotetext{
2 (2) is adapted from an example in Cohen 2002.

${ }^{3}$ See e.g. DeRose 2009: 194, Fantl \& McGrath 2009a: 208, Hawthorne 2004: 177n, Schaffer 2006: 94n, \& Stanley 2005: 106. Note that examples like (1)-(2) can sometimes seem true (and not strange). The problem is that SSI implies that examples like (1)-(2) can be true even if we suppose that the traditional 'epistemic' factors - the subject's belief state, the reliability of her methods, etc.-remain constant across the actual situation and the relevant counterfactual situation in which the subject has more at stake, or is considering additional error possibilities. (For a more careful account of what to hold constant - one that aims to respect the fact that some proponents of SSI claim that there is a constitutive tie between 'non-epistemic' factors, such as stakes, and some traditional epistemic factors, such as evidence — see DeRose's (2009: 194-6) appeal to "truth relevant" factors. Such subtleties need not concern us here.)
} 
However, such utterances also seem strange. As in the case of (1) and (2), our judgment that examples like (3) seem strange would appear to indicate that knowledge does not come and go merely with differences in 'non-epistemic' factors, and that SSI is therefore false. $^{4}$

Examples like (1)-(3) suggest that 'strange-but-true' conditionals pose a serious problem for those advocating SSI. Rival theorists do not appear to share this problem. Classical invariantists, sceptical invariantists, and (most) contextualists reject the claim that knowledge is constitutively tied to 'non-epistemic' factors, such as stakes and salient error possibilities. ${ }^{5}$ On those rival theories, then, knowledge does not come and go merely with changes in non-epistemic factors, and examples like (1)-(3) come out false. ${ }^{6}$

\section{§1. Responding to the Problem}

A prominent response to the preceding problem for SSI draws attention to our judgments regarding some other conditionals (Hawthorne 2004: 177n, Stanley 2005: 113-4, Fantl \& McGrath 2009a: 209). Suppose Henry looks out at a real barn as he is driving through ‘fake barn' country (Goldman 1976), and a speaker utters (4).

\footnotetext{
${ }^{4}$ A similar problem arises regarding examples like the following:

(3)* If Jean is considering the possibility that the table is white but illuminated by red lights, she doesn't know that the table is red. But if she isn't considering improbable ways she might be mistaken, she knows that the table is red.

Note, though, that the most common forms of SSI tie knowledge to practical factors, such as stakes, but not to the error possibilities salient to the subject. These accounts can presumably avoid problems with examples like (2) and (3)*.

${ }^{5}$ For useful characterisation of the relevant positions in the debate, see e.g. DeRose (2009: 1-46) \& MacFarlane (2014: ch. 8).

${ }^{6}$ In $\S 3$, we shall look at some 'metalinguistic' examples, similar to (1)-(3), that might seem to pose a problem for contextualists about 'know'.
} 
(4) Henry doesn't know he's seeing a barn. But if there weren't those fake barns around, Henry would know he's seeing a barn.

Such an utterance seems strange. ${ }^{7}$ Similarly, suppose Henry looks out at a real barn as he is driving through (unspecified) countryside, and a speaker utters (5).

(5) If there are fake barns nearby, Henry doesn't know he's seeing a barn. But if there aren't any fake barns nearby, then he does know he's seeing a barn.

Such utterances also seem strange (Stanley 2005: 114n). Our judgment that examples like (4) and (5) seem strange would appear to indicate that knowledge does not come and go merely with a difference in the presence of fake barns. However, all (or almost all) nonsceptical epistemologists claim that although Henry lacks knowledge in Goldman's famous Gettier case, he possesses knowledge in the relevant 'good case', where there are no fake barns around. ${ }^{8}$ As a result, it seems that all (or nearly all) non-sceptical epistemologists must accept that the envisaged utterances of (4) and (5) can be true, and that knowledge does come and go merely with a difference in the presence of fake barns. Examples like (4) and (5) therefore pose an apparently serious problem for non-sceptical epistemologists in general.

\footnotetext{
${ }^{7}$ See Hawthorne 2004: 177n, Stanley 2005: 113-4, Fantl \& McGrath 2009a: 209. DeRose (2009: 197-8) and Blome-Tillmann (2009: 321) report somewhat different judgments - a point I return to later (§3).

${ }^{8}$ See Goldman (1976) for the original presentation of the 'fake barn' case. (Goldman credits the example to Carl Ginet.) Some concerns have been raised regarding our judgments in the original fake barn case; see e.g. DeRose 2009: 23n, Gendler \& Hawthorne 2005, and, for relevant empirical work, Colaço et al. 2014. But note that similar 'strange-but-true' conditionals plausibly arise in regard to other examples, such as the various 'fake ring' cases discussed in Gendler \& Hawthorne (2005: 334-8); the arguments of the present paper could be recast in terms of those alternative examples. Of course, it should be acknowledged that further empirical work may ultimately upend claims about our judgments in all the relevant cases. This would serve to undercut the argument for contextualism given in the present work-but it would also undercut the defence of SSI being considered.
} 
Drawing on examples like (4) and (5), subject-sensitive invariantists have offered the following simple response to the problem posed by (1)-(3). Non-sceptical epistemologists in general face problems with 'strange-but-true' conditionals. Consequently, it is not particularly troubling that SSI faces problems with 'strange-but-true' conditionals. ${ }^{9}$ In short: SSI is in good company. ${ }^{10}$

\section{§2. Contextualism}

The problem with this subject-sensitive invariantist response is that it isn't true that nonsceptical epistemologists in general face problems with strange-but-true conditionals. One large and mainstream group of non-sceptical epistemologists - contextualists about 'know' - are able to avoid problems not only with examples like (1)-(3), but also with examples like (4)-(5).

A standard contextualist proposal is that a subject must be able to rule out salient ways she might be mistaken in order to be truly said to 'know'. In more careful terms, a standard contextualist proposal is that a use of 'know' in a context, c, expresses a relation, $\mathrm{K}$, such that in order for a subject to stand in $\mathrm{K}$ to some proposition, $\mathrm{P}$, the subject must be able to

\footnotetext{
${ }^{9}$ All else equal, a theory that results in fewer problematic judgments is presumably to be preferred. Advocates of SSI must presumably accept examples like (1)-(3) and (4)-(5) as strange-but-true, whereas rival non-sceptical theorists need (at most) accept only (4)-(5) as strange-but-true. The observation that (4)(5) appear to pose a general problem for non-sceptical theorists therefore does not altogether remove the strike against SSI issuing from (1)-(3).

${ }^{10}$ See Hawthorne 2004: 177n, Stanley 2005: 113-4, Fantl \& McGrath 2009a: 209. The subject-sensitive invariantist response to examples like (1)-(3) given in the main text closely resembles Fantl \& McGrath (2009a: 209). Stanley (2005: 113-4, drawing on p.c. with John Hawthorne) presents a slightly different response. Stanley suggests that examples like (4)-(5) are a problem for reliabilism, and since another popular view (reliabilism) has similar problems to SSI, strange-but-true conditionals are not a serious objection to SSI. This is clearly a much weaker response than the one presented in the main text. After all, if strange-buttrue conditionals are problems merely for SSI and reliabilism, don't such conditionals supply good reason to reject both those theories (DeRose 2009: 197-8)? The arguments to follow also further weaken Stanley's argument, since it is argued that a contextualist - and so, plausibly, a reliabilist who endorses contextualism - need not hold that the envisaged utterances of (4)-(5) are strange-but-true. Thus, the arguments to follow suggest that (4)-(5) are not a problem for reliabilism per se (as Stanley suggests), but rather a problem for those reliabilists who embrace non-sceptical invariantism.
} 
rule out ways she might be mistaken with respect to $\mathrm{P}$ that are salient in c. Assume this standard contextualist proposal is on the right track. ${ }^{11}$

Consider (5) uttered in regard to a situation in which Henry looks out at a real barn as he is driving through the countryside. By uttering (5), the speaker draws especial focus to fake barns. But 'fake barns' are (by definition) non-barns that look just like real barns to those driving past (Goldman 1976). Thus, by uttering (5), the speaker plausibly makes very salient that one way a subject like Henry could come to mistakenly believe that he is seeing a barn is by looking at a fake barn. Our standard contextualist proposal would therefore seem to imply that the uses of 'know' in (5) will express a relation, $\mathrm{K}^{*}$, such that in order for Henry to stand in $\mathrm{K}^{*}$ to the proposition that he is seeing a barn, he must be able to rule out that he is seeing a fake barn.

Henry is described as looking out at a real barn as he is driving through the countryside. Thus, whether or not there are fake barns in his vicinity, it seems that Henry is going to be unable to rule out that he is seeing a fake barn. In either case, it seems that Henry is going to have a visual experience as of a barn, and that visual experience is going to leave him unable to rule out that he is seeing a fake barn. Given our standard contextualist proposal, it follows that the envisaged utterance of (5) will plausibly be false - and not 'strange-buttrue' - because the utterance of the second conjunct of (5) will plausibly be false. Even if there are no fake barns in his vicinity, Henry will be unable to rule out that he is seeing a fake barn, and so he will not stand in $\mathrm{K}^{*}$ to the proposition that he is seeing a barn. Given our standard contextualist proposal, it is also unsurprising that the envisaged utterance of

\footnotetext{
${ }^{11}$ For relevant exposition and defence of contextualism about 'know', see e.g. Lewis 1996, Cohen 1988, 1999, DeRose 1995, 2009, Ichikawa 2011 and Blome-Tillmann 2014. To keep things simple, I am focusing on a simple-minded contextualist proposal that emphasises ruling out salient error possibilities (as in Lewis 1996). But I take it that an explanatory strategy similar to the one outlined in the main text is available to many other contextualists. See $\S 3$ for relevant discussion.
} 
(5) seems strange. It seems strange because whether or not there are fake barns in his vicinity clearly makes no difference to whether Henry stands in $\mathrm{K}^{*}$ to the proposition that he is seeing a barn - in either case, he will fail to stand in $\mathrm{K}^{*}$ to that proposition, since he will be unable to rule out that he is seeing a fake barn. ${ }^{12}$

It is important to stress that, despite offering the preceding account of examples like (5), the contextualist is still able to respect the claim that whether or not Henry is surrounded by fake barns often impacts whether Henry can be truly said to 'know' that he is seeing a barn. Our contextualist proposes that, in contexts where the possibility of fake barn deception is salient, Henry must be able to rule out that he is seeing a fake barn in order to be truly said to 'know' that he is seeing a barn. This requirement holds whether or not Henry is surrounded by fake barns, but it only concerns uses of 'know' in contexts where the possibility of fake barn deception is salient. In regard to contexts where this kind of unusual/unlikely deception is not salient - and let's face it, this is the more common kind of context - the contextualist is free to maintain that whether or not Henry is surrounded by fake barns importantly impacts whether he can be truly said to 'know' that he is seeing a barn. $^{13}$

\footnotetext{
${ }^{12}$ Parallel remarks apply to (4). For relevant discussion of how the contextualist takes 'knows' to behave when uttered in temporally/modally shifted contexts (as in (4)), see e.g. DeRose (2009: esp. 204-6).

${ }^{13}$ To secure this result, the contextualist might propose that an additional requirement on true application of 'know' (in any context) is that the subject be able to rule out the error possibilities that are 'close' or could easily obtain (cf. Sainsbury 1997, Sosa 1999, Williamson 2000). This requirement plausibly implies that if Henry is surrounded by fake barns, he cannot be truly said to 'know', in any context, that he is seeing a barn. But if Henry is not surrounded by fakes, this requirement will often leave open that Henry can be truly said to 'know'. (Note, though, that the contextualist need not adopt this proposal. There may be some benefits to a contextualist account that allows that, in at least some contexts, Henry can be truly said to 'know' even if he is surrounded by fake barns; see e.g. DeRose 2009: 33n \& Greco 2017 for some relevant discussion.)
} 
So where does this leave us? The immediate conclusion is that, since contextualists about 'know' can apparently avoid problems with 'strange-but-true' conditionals, appeal to examples like (4)-(5) does little to assuage the problem that examples like (1)-(3) pose for SSI. ${ }^{14}$ At the same time, it seems that we have identified a new argument in favour of contextualism about 'know'. In attempting to alleviate the problem arising from examples like (1)-(3), subject-sensitive invariantists have drawn attention to a problem for nonsceptical epistemological theories in general: namely, that such theories imply that utterances of (4) and (5) are strange-but-true. As contextualism about 'know' supplies a neat response to this general problem for non-sceptical accounts, it seems we have identified a new argument in favour of the contextualist position.

\section{§3. Objections and Replies}

Let me close by considering three possible objections to the arguments put forward above. The first objection is that the preceding contextualist account of examples like (4) and (5) rests on an implausible account of the semantic effects of salience. A more plausible account, it might be insisted, holds that the effect of an error possibility being salient is at most to exert a kind of semantic pressure. For example, it might be insisted that the possibility of fake barn deception being salient at most generates semantic pressure towards uses of 'know' expressing a relation, $\mathrm{K}^{*}$, such that a subject can stand in $\mathrm{K}^{*}$ to the proposition that she is seeing a barn only if she can rule out that she is seeing a fake barn. This opens up the possibility that there will be contexts in which this salience-related

\footnotetext{
${ }^{14}$ The arguments of the present paper might suggest that those seeking to defend merely the antiintellectualist element of SSI - viz. that knowledge is constitutively tied to 'non-epistemic' factors - could avoid problems with strange-but-true conditionals if they embrace contextualism about 'know'. I cannot explore that possibility here.
} 
semantic pressure is overridden by other factors, and in which utterances of (4) and (5) may therefore come out true.

However, rather than being a cause for concern, such considerations plausibly represent a further reason to favour the contextualist proposal. It is interesting to note that DeRose (2009: 197-8) reports finding examples similar to (4) "[not] so paradoxical", and BlomeTillmann (2009: 321) claims to have "very strong intuitions" that examples similar to (4) are true. ${ }^{15}$ Allowing that the salience of error possibilities merely exerts a kind of semantic pressure plausibly enables us to explain these judgments as well, since we can suppose that DeRose and Blome-Tillmann are imagining (4)-(5) being uttered in contexts in which overriding factors are present. ${ }^{16}$ For example, perhaps these authors are imagining (4)-(5) being uttered in a context where the issue of how easily Henry could be mistaken is in focus. Contemporary discussion of the fake barn case often emphasises the fact that if Henry is surrounded by fake barns, Henry could so easily be seeing a fake barn, and thus could so easily be wrong, whereas if there are no fake barns in his vicinity, this is not the case (see e.g. Pritchard 2016). If this (allegedly) epistemologically significant contrast is in focus in the context in which (4)-(5) are being uttered, it might be natural to suppose that the speaker is intending her uses of 'know' to capture that contrast. In combination with standard 'accommodation' considerations (Lewis 1979), this may be sufficient to overcome the semantic pressure generated by the salience of the possibility of fake barn deception. Thus, far from being a problem for the contextualist proposal, allowing for a more nuanced account of the semantic effects of salience plausibly enables the

\footnotetext{
${ }^{15}$ These authors do not consider or comment on examples like (5). Note that Blome-Tillmann and DeRose's remarks are (as far as I'm aware) the extant contextualist attempts to undercut the defence of SSI by appeal to examples like (4)-(5). The contention of the present paper is that there is a far better way to go - one that respects the fact that others find (4)-(5) genuinely strange, undercuts the proposed defence of SSI, and supplies a new argument for contextualism about 'know'.

${ }^{16}$ Note that this is not the only possible contextualist explanation for DeRose and Blome-Tillmann's judgments; see the discussion of the next objection, and fn. 18 .
} 
contextualist to better capture judgments about examples like (4) and (5) - to explain why utterances of (4) and (5) have struck many authors as strange, but also explain why they might not invariably seem strange.

A second objection is that contextualist accounts centring on appeal to salient error possibilities, even those that claim that salience merely exerts a kind of semantic pressure, are simply implausible. In order to be plausible, it might be alleged, contextualists need to focus their accounts on the error possibilities that are being taken seriously (see e.g. Blome-Tillmann 2012). On this kind of picture, it is only possibilities that are being taken seriously that generate the relevant kind of semantic pressure. Once again, however, there is no real cause for concern here. It seems that by uttering (4)-(5), the speaker invites the hearer to take the possibility of fake barn deception seriously. Thus, although the possibility of fake barn deception might not invariably be taken seriously in contexts in which (4)-(5) are uttered, it seems plausible that it generally will be. ${ }^{17}$ Our amended contextualist proposal is therefore still able to explain why utterances of (4)-(5) have struck many as strange. Of course, if the possibility of fake barn deception is not invariably taken seriously in contexts in which (4)-(5) are uttered, our amended proposal presumably allows that (4)-(5) can sometimes be uttered truly. But as argued above, that plausibly represents a benefit of the contextualist approach, rather than a cost. ${ }^{18}$

\footnotetext{
${ }^{17}$ Notice that if relevant utterances of (4) or (5) are to strike hearers as true, those hearers presumably need to appreciate that the reason why Henry lacks 'knowledge' if he is surrounded by fakes, but possesses 'knowledge' if he is not surrounded by fakes is that in the former case he is much more susceptible to fake barn deception than he is in the latter case. This would seem to suggest that for utterances of (4) and (5) to actually strike hearers in the context of utterance as true, the possibility of fake barn deception needs to be taken seriously.

${ }^{18}$ A more recherché objection. A distinction is sometimes drawn between considering a possibility as actual (as a way the world might actually be) and considering it as counterfactual (as a way the world might have been) - see e.g. Chalmers 2002: §3. It might be suggested that when uttering (4) or (5) what most immediately happens is that we consider possibilities in which Henry is looking at a fake barn as ways things could have been for Henry, rather than as ways things might actually be for Henry. But it might be proposed that insofar as considering possibilities has an impact on what possibilities a subject must be able
} 
Let's consider a final objection. In response to our contextualist manoeuvring, nonsceptical epistemologists apparently forced to accept some combination of (1)-(5) as strange-but-true (that is, non-sceptical invariantists ${ }^{19}$ ) might draw attention to examples like the following:

(6) Brian doesn't know that the table is red. But if we weren't considering improbable ways he might be mistaken, such as that the table is white but illuminated by red lights, I would speak truly in uttering 'Brian knows that the table is red'.

Given standard contextualist accounts, it seems that such utterances could easily be true. However, such utterances seem strange (see e.g. Fantl \& McGrath 2009a: 50). It might therefore seem that although the contextualist avoids difficulty with examples like (1)-(5), there are other strange-but-true conditionals that affect the contextualist position. ${ }^{20}$ If that's right, then it might seem that strange-but-true conditionals cannot after all represent

to rule out in order to 'know', it is only the possibilities that are being considered as actual that have an impact. (Note that the relevant 'actual' situation here is Henry's actuality, not ours.)

Once again, these reflections represent no serious cause for concern. One option for the contextualist is obviously just to deny that it is only possibilities that are being considered as actual that impact the requirements on 'know'. But suppose that the proposal is right. Given how Henry's actual situation is described (Henry looks out at a real barn as he is driving through the countryside), it seems plausible that even if, when (4)-(5) are uttered, we don't consider possibilities in which Henry is looking at a fake barn as actual as immediately as we consider them as counterfactual, it nevertheless seems plausible that many people will consider them as actual fairly quickly. At the same time, as noted above, not all authors react to utterances of (4)-(5) by declaring that such utterances seem strange. A further explanation for their reactions could be that the proposal being considered is correct, and that these authors are imagining (4)-(5) being uttered in contexts where possibilities in which Henry is looking at a fake barn are considered merely as counterfactual and not as actual.

${ }^{19}$ Non-sceptical invariantists are either classical or subject-sensitive invariantists. As noted in $\S 1$, classical invariantists - those non-sceptical invariantists who reject the claim that knowledge is constitutively tied to 'non-epistemic' factors - do not face a challenge from examples like (1)-(3). Nevertheless, such theorists presumably face a challenge from examples like (4)-(5).

${ }^{20}$ Stanley (2005: 110-3) argues that Lewis' (1996) particular brand of contextualism has problems with strange-but-true conditionals distinct from examples like (6). For replies to Stanley's argument, see Fantl \& McGrath (2009b: 181) and Blome-Tillmann (2009: 321-4). 
an objection to, or reason to favour, any particular non-sceptical account, since such conditionals are in fact a problem for all non-sceptical accounts.

There are at least two replies to be made here. One thing to note is that the strangeseeming utterances of (6) do not come out true given some non-standard forms of contextualism, such as relativism. Indeed, MacFarlane (2005, 2014: ch. 8) introduced the relativist position precisely as a way to counter objections to contextualism issuing from 'metalinguistic' examples like (6). ${ }^{21}$ One might therefore suggest that the take-home message from examples like (6) is that relativism is the only non-sceptical account to avoid problems with strange-but-true conditionals, and thus that the arguments of the present paper represent a surprising new argument for relativism.

This would be an interesting result. However, relativism is not a mainstream position. Other non-sceptical theorists might therefore still contend that since all mainstream nonsceptical positions suffer problems with strange-but-true conditionals, such conditionals are not especially concerning for any particular non-sceptical account.

Is a reply available that avoids this weakness? Arguably, yes. It seems that if the standard contextualist could provide an independently plausible explanation of why utterances such as (6) seem strange despite being true, such utterances would not in fact represent a problem for standard contextualism. In this regard, notice that 'meta-linguistic' strangebut-true conditionals arise in regard to other expressions which are widely held to be context sensitive (in a standard way). Consider the following:

\footnotetext{
${ }^{21}$ For relativist treatment of an example similar to (6), see MacFarlane (2014: 197). For considerations of space, I cannot recount such an explanation here.
} 
(7) That surface isn't flat. But if I hadn't just drawn attention to all those very tiny bumps, I would speak truly in uttering 'That surface is flat'.

Utterances of (7) also seem strange, but presumably such utterances could easily be true given contextualism about 'flat'. ${ }^{22}$ Assuming that ' $\mathrm{flat}$ ' is indeed context sensitive, our judgments regarding such utterances appear to indicate that the context sensitivity of 'flat' is something that is not always obvious to speakers. If that's right, then it seems that we have some independent motivation to maintain that utterances of (6) seem strange because 'know' is just another example of an expression whose context sensitivity is not always obvious to speakers (see Cohen 1999: 81-2, 2001: 90-1; Blome-Tillmann 2014: 96-112). This suggests that examples like (6) do not in fact represent a genuine problem for standard contextualist accounts of 'know', and that non-sceptical invariantists cannot simply point to examples like (6) as evidence that standard contextualists face similar problems with strange-but-true conditionals. ${ }^{23}$

\section{$\S 4$. Concluding remarks}

Contextualists appear to be left in an enviable position. Their accounts not only avoid the familiar problem for SSI issuing from examples like (1)-(3), ${ }^{24}$ but also supply a neat answer to a more general problem for non-sceptical theories issuing from 'fake barn'

\footnotetext{
${ }^{22}$ To any readers not sensing discomfort with (7), I reiterate Lewis' (1996: 550) familiar advice to "hear it afresh".

${ }^{23}$ The argument presented in the main text is one way to argue that examples like (6) do not pose a similar problem for standard contextualism that examples like (1)-(3) and/or (4)-(5) apparently pose for nonsceptical invariantism. There are at least two further ways to argue for this conclusion. One way is to argue that it is less important for a theory to capture judgments regarding 'metalinguistic' examples (i.e. those examples, like (6), where the target expression is mentioned rather than used) since the meaning of a term is primarily determined by how it is used rather than how it is mentioned (cf. DeRose 2009: 153-4). Another way is to argue that the contextualist faces fewer strange-but-true conditionals than rival non-sceptical accounts, and that such conditionals are therefore a more serious problem for rival views than for contextualism (cf. fn. 9).

${ }^{24}$ As indicated in $\S 3$, contextualists are also able to avoid problems with 'metalinguistic' examples similar to (1)-(3), such as (6).
} 
examples like (4)-(5). That answer brings a bounty of riches: it respects the observation that (4)-(5) seem genuinely strange, undercuts an important defence of SSI, and supplies a quick new argument for contextualism about 'know'. ${ }^{25^{*}}$

$\underline{\text { References }}$

Blome-Tillmann, M. 2009. Contextualism, Subject-Sensitive Invariantism, and the Interaction of 'Knowledge'-Ascriptions with Modal and Temporal Operators. Philosophy and Phenomenological Research, 79, 315-331.

Blome-Tillmann, M. 2012. Presuppositional Epistemic Contextualism and the Problem of Known Presuppositions. In J. Brown \& M. Gerken (Eds.), Knowledge Ascriptions (pp. 104-119). Oxford: Oxford University Press.

Blome-Tillmann, M. 2014. Knowledge and Presuppositions. Oxford: Oxford University Press.

Colaço, D., Buckwalter, W. , Stich, S., \& Machery, E. 2014. Epistemic Intuitions in FakeBarn Thought Experiments. Episteme, 11, 199-212.

Chalmers, D. 2002. Does Conceivability Entail Possibility? In T. Gendler \& J. Hawthorne (Eds.), Conceivability and Possibility (pp. 145-200). Oxford University Press.

Cohen, S. 1988. How to Be a Fallibilist. Philosophical Perspectives, 2, 91-123.

\footnotetext{
${ }^{25}$ To direct future research, it may be useful to think of the positive argument for contextualism offered here as presenting a kind of challenge for the contextualist's non-sceptical opponents. As noted in the discussion of (6), it seems plausible that strange-but-true conditionals do not pose a genuine problem for a theory if some suitably motivated explanation can be found for why those conditionals seem strange despite being true. The challenge for the contextualist's non-sceptical opponents would therefore seem to be to provide a suitably motivated explanation for why examples like (1)-(3) and/or (4)-(5) seem strange despite being true. If that challenge can be met, it would undercut the positive argument for contextualism presented above; if not, that argument remains in force.

* Thanks to Jessica Brown, Patrick Greenough, Dirk Kindermann, Daniele Sgaravatti, and an anonymous referee for helpful comments and discussion.
} 
Cohen, S. 1999. Contextualism, Skepticism, and the Structure of Reasons. Philosophical Perspectives, 13, 57-89.

Cohen, S. 2001. Contextualism Defended: Comments on Richard Feldman's Skeptical Problems, Contextualist Solutions. Philosophical Studies, 103, 87-98.

Cohen, S. 2002. Basic Knowledge and the Problem of Easy Knowledge. Philosophy and Phenomenological Research, 65, 302-29.

DeRose, K. 2009. The Case for Contextualism, vol.1. Oxford: Clarendon Press.

Fantl, J. \& McGrath, M. 2007. On Pragmatic Encroachment in Epistemology. Philosophy and Phenomenological Research, 75, 558-589.

Fantl, J. \& McGrath, M. 2009a. Knowledge in an Uncertain World. Oxford: Oxford University Press.

Fantl, J. \& McGrath, M. 2009b. Critical Study of John Hawthorne's Knowledge and Lotteries and Jason Stanley's Knowledge and Practical Interests. Nô̂s, 43, 178-92.

Gendler, T. \& Hawthorne, J. 2005. The Real Guide to Fake Barns: A Catalogue of Gifts from Your Epistemic Enemies. Philosophical Studies, 124, 331-52.

Goldman, A. 1976. Discrimination and Perceptual Knowledge. The Journal of Philosophy, 73, 771-791.

Greco, J. 2017. Contextualism and Gettier Cases. In J. Jenkins Ichikawa (Ed.), The Routledge Handbook of Epistemic Contextualism (pp. 190-202). Oxford: Routledge.

Hawthorne, J. 2004. Knowledge and Lotteries. Oxford: Clarendon.

Ichikawa, J. 2011. Quantifiers and Epistemic Contextualism. Philosophical Studies, 155, 383-98.

Lewis, D. 1979. Scorekeeping in a Language Game. Journal of Philosophical Logic, 8, $339-59$.

Lewis, D. 1996. Elusive Knowledge. Australasian Journal of Philosophy, 74, 549-567. 
MacFarlane, J. 2005. The Assessment Sensitivity of Knowledge Attributions. In T.S.

Gendler \& J. Hawthorne (Eds.), Oxford Studies in Epistemology: Volume 1 (pp. 197-233).

Oxford: Oxford University Press.

MacFarlane, J. 2014. Assessment Sensitivity: Relative Truth and Its Applications. Oxford: Oxford University Press.

Pritchard, D. 2016. Epistemic Risk. The Journal of Philosophy, 113, 550-571.

Sainsbury, M. 1997. Easy Possibilities. Philosophy and Phenomenological Research, 57, 907-919.

Schaffer, J. 2006. The Irrelevance of the Subject: Against Subject Sensitive Invariantism. Philosophical Studies, 127, 87-107.

Sosa, E. 1999. How to Defeat Opposition to Moore. Philosophical Perspectives, 13, 141153.

Stanley, J. 2005. Knowledge and Practical Interests. Oxford: Clarendon Press.

Weatherson, B. 2012. Knowledge, Bets, and Interests. In J. Brown \& M. Gerken (Eds.), Knowledge Ascriptions (pp. 75-103). Oxford: Oxford University Press.

Weatherson, B. 2017. Interest-Relative Invariantism. In J. Jenkins Ichikawa (Ed.), The Routledge Handbook of Epistemic Contextualism (pp. 250-254). Oxford: Routledge.

Williamson, T. 2000. Knowledge and Its Limits. Oxford: Oxford University Press. 